\title{
De rechtsverhouding tussen erfpachter en erfverpachter
}

\author{
Bespreking van het proefschrift van mr. J. Broese van Groenou
}

\author{
Mr.J.M. Milo*
}

\begin{abstract}
1 Inleiding
Eindelijk! De rechtsverhouding tussen erfpachter en erfverpachter is ten gronde eigentijds historisch fraai onderzocht door J. Broese van Groenou. ${ }^{1}$ Op deze studie promoveerde zij in 2019 aan de Open Universiteit bij Mertens en Ernes. Het is een omvangrijk onderzoek aan de hand van een zeer uitgebreide beschrijving van met name rechtspraak. In volgend verband met deze studie verschenen inmiddels van haar hand een bondig cahier ${ }^{2}$ en een puntig artikel. ${ }^{3}$ Eerder publiceerde auteur een overzichtsartikel over de erfpachtverhouding, dat ook dienstbaar was aan haar proefschrift. ${ }^{4}$ Erfpacht is een zakelijk recht dat de erfpachter de bevoegdheid geeft eens anders onroerende zaak te houden en te gebruiken, aldus art. 5:85 BW. In de akte van erfpacht kunnen allerhande bedingen worden opgenomen, waarbij de wet de grootst mogelijke vrijheid biedt aan de eigenaar en erfverpachter om de bevoegdheden en verplichtingen (de canon, de duur, het gebruik, de overdracht of splitsing, de opzegging) invulling te geven. Erfpacht was eerder onderwerp van promotieonderzoek. Voncks studie verscheen in $2013^{5}$ en iets langer terug treffen we Reepmakers dissertatie uit 1931. ${ }^{6}$ Broese van Groenou heeft haar onderzoek naar erfpacht vanuit het (ook verbintenisrechtelijke) perspectief van de rechtsverhouding tussen erfverpachter en erfpachter geschreven, en daarmee afgebakend van het gebruikelijke juist goederenrechtelijk gekleurde perspectief van vestiging, overdracht, of flexibiliteit ten behoeve van gebruik en financiering (Vonck) of het zakelijke recht van erfpacht als zodanig in zijn systematische ontwikkeling in de stromen van Romeins en oud-vaderlands recht (Reepmaker). Zij kwalificeert haar studie in het voorwoord als 'een aanvulling op' die
\end{abstract}

* Mr. J.M. Milo is universitair hoofddocent aan de Universiteit Utrecht

1. J. Broese van Groenou, De rechtsverhouding tussen erfpachter en erfverpachter (diss. Heerlen), Deventer: Wolters Kluwer 2019 (hierna: Broese van Groenou 2019).

2. J. Broese van Groenou, Erfpacht, Nijmegen: Ars Aequi Libri 2020.

3. J. Broese van Groenou, Twee stellingen, WPNR 2019, afl. 7271, p. 141-143.

4. J. Broese van Groenou, Het toestemmingsvereiste bij erfpachtverhoudingen, WPNR 2016, afl. 7106, p. 343-355.

5. F.J. Vonck, De flexibiliteit van het recht van erfpacht (diss. Groningen), Den Haag: Boom Juridische uitgevers 2013.

6. A.A. Reepmaker, Het recht van erfpacht (diss. Leiden), Leiden: S.C. van Doesburgh 1931. studies. Daarmee doet zij haar onderzoek tekort. Het vult niet alleen aan, het loutert ook. Het werd tijd dat er eens goed naar die rechtsverhouding tussen erfverpachter en erfpachter gekeken werd, want die kwam er inderdaad wel wat stiefmoederlijk vanaf.

\section{Inhoud van het boek}

Het is een omvangrijke studie geworden waarin met veel oog voor detail beschrijvingen worden gegeven van argumentaties omtrent erfpacht van wetgevende, rechtsgeleerde, maar in hoofdzaak van jurisprudentiële aard, waarop de eigen analyse is gefundeerd. De uitgebreide beschrijvingen brengen veel moois onder de aandacht; de eigen analyse verdwijnt daarbij af en toe wel wat uit zicht. De inleiding behandelt de toepassingen van het recht van erfpacht - gebruik van grond voor natuur, recreatie, agrarisch of bedrijfsmatig gebruik, of om te wonen - door publieke of private (rechts)personen in erfpacht gegeven en genomen, met vaak in algemene voorwaarden vastgelegde rechten en plichten. Erfpacht wordt genormeerd op een speelveld met meer dwingende bepalingen van het goederenrecht en de partijautonomie van de contracterende personen in het verbintenissenrecht. Uit de toepassingen in rechtspraak van erfpacht blijkt van veel kommer en kwel, vaak over de canonverplichting, aan de kant van de erfpachter, meest een particulier, tegenover een 'professionele' erfverpachter; een problematische en ongelijkwaardige verhouding die contrasteert met de neutrale weergave die uit wet, jurisprudentie en rechtsgeleerde literatuur opstijgt, aldus de auteur. ${ }^{7}$ Welke normen moeten betrokken zaaksgerechtigden in hun rechtsverhouding in acht nemen? De wettelijke onduidelijkheid over de verbintenisrechtelijke zijde van de rechtsverhouding tussen erfverpachter en erfpachter vormt de aanleiding voor geschillen, zo blijkt ook nog eens uit dit boek. ${ }^{8}$ Uit die praktische relevantie verschijnt dan de onderzoeksvraag 'hoe (...) de rechtsverhouding tussen erfpachter en erfverpachter juridisch gekwalificeerd [moet] worden', waarbij de uitoefening van de rechten en verplichtingen jegens elkaar wordt onderzocht. Die kwalificatie van een vermogensrechtelijke rechtsverhouding kan goederenrechtelijk of verbintenisrechte-

7. Broese van Groenou 2019, p. 19.

8. Broese van Groenou 2019, p. 22 
lijk zijn, zo geeft ons de systematiek van het vermogensrecht. Toch is het zo eenvoudig niet, dat maakt het onderzoek goed duidelijk. In ons hedendaagse goederenrecht neemt relativering toe, en zijn open normen en flexibiliteit alom tegenwoordig. In het erfpachtrecht is daarvan eens te meer sprake, omdat binnen de grenzen van dat goederenrechtelijke recht (zie art. 3:81 jo. art. 5:85 e.v. BW) een maximale ruimte wordt geboden om bevoegdheden en verplichtingen van erfverpachter en erfpachter ten aanzien van een onroerende zaak inhoud te geven.

De terminologie is in dit proefschrift weloverwogen gekozen 'erfverpachter' in plaats van grondeigenaar, omdat er in de kwalificatie als eigenaar een impliciete erkenning van een zwaarwegender rechtspositie schuilt. ${ }^{9}$ De vraagstelling wordt gevolgd door een uiteenzetting van de methodologie (p. 1-28). Het tweede hoofdstuk gaat in op het begrip rechtsverhouding in het vermogensrecht (p. 29-166), en van daaruit wordt die rechtsverhouding tussen erfverpachter en erfpachter voor wat betreft de bevoegdheden en verplichtingen van erfverpachter en erfpachter telkens onderzocht. Eerst zoals deze meestal zijn opgenomen in de algemene erfpachtvoorwaarden (hoofdstuk 3, p. 167-252), dan toegespitst op het vereiste van toestemming van de erfverpachter voor (rechts)handelingen ten aanzien van de onroerende zaak door de erfpachter (hoofdstuk 4, p. 253-316), op de bevoegdheid van herziening van de canon (hoofdstuk 5, p. 317-470) en op de beëindiging van het recht van erfpacht (hoofdstuk 6, p. 471-632). De conclusie volgt in hoofdstuk 7 (p. 633-666), waarna een korte samenvatting volgt in de Nederlandse (p. 667-670) en een wat langere (prima!) in de Engelse taal (p. 671-683). Een literatuurlijst en een register op jurisprudentie en trefwoorden completeren de studie. De kwalificatie van de rechtsverhouding tussen erfverpachter en erfpachter en de daarop toepasselijke rechtsnormen zijn noch slechts goederenrechtelijk, noch slechts verbintenisrechtelijk van aard. De rechtsverhouding tussen erfverpachter en erfpachter is altijd een samengestelde, waarvan ook het consumentenrecht, mensenrechten en het publiekrecht deel uitmaken.

\section{Methode}

Het onderzoek geschiedt volgens een methodiek die expliciet stoelt op Smits' uiteenzettingen, ${ }^{10}$ waarbij met name wordt voortgebouwd op de gedachte dat recht niet alleen door wetgever en (hogere) rechtspraak wordt gevormd, maar ook van 'onderop' door lagere rechtspraak en in het maatschappelijk verkeer gestalte krijgt. Dat is uitstekend, want rechtspraak - ook lagere - wordt nu juist in dit proefschrift onderzocht, en wel zeer uitgebreid. Een dergelijk veelomvattend en beschrijvend onderzoek van twee eeuwen rechtsontwikkeling is niet alleen zeer verdedigbaar, maar zelfs onmisbaar, omdat alleen een dergelijk onderzoek van jurisprudentie, doctrine, wetgeving en 'zelfregulering' - 'gewoonte' zou de traditionele

9. Broese van Groenou 2019, p. 26.

10. J.M. Smits, Omstreden rechtswetenschap, Den Haag: Boom Juridische uitgevers 2009; Broese van Groenou 2019, p. 24-27. benaming zijn - die rechtsverhouding tussen erfverpachter en erfpachter aan het licht kan brengen.

Over de in het onderzoek gevolgde methode nog wel het volgende. De methode van rechtsvorming staat evident in oorzakelijk verband met de juridische argumentatie die in rechtspraak en doctrine zichtbaar wordt, en die methode is door de jaren heen nogal aan verandering onderhevig, zeker als de onderzochte periode twee eeuwen betreft. Voor die verschillende rechtstheorieën - alle nuances tussen wetspositivisme (Opzoomer en Land) en vrije(re) rechtsvinding (Molengraaff, Moltzer en Paul Scholten) - had dit onderzoek een klein beetje ruimte moeten bieden in de beschrijving. Paul Scholtens Algemeen deel (1931) ontbreekt, privaatrechtstheorie uit de lange negentiende eeuw ontbreekt eveneens, terwijl al die schrijvers met hun door die theorieën en methoden gestuurde argumentatie wel de inhoudelijke erfpachtrevue passeren. Daaruit zouden de volgende vragen naar voren komen: Welke rechtsbronnen accepteren wij? Hoe dwingend is de wet of een akte? Welke argumenten mogen meewegen bij de analyse van wat rechtens is, voor objectief recht of bij de beoordeling van een geschil? Kunnen alle belangen wel deugdelijk worden meegewogen? Dat is juist van belang bij een rechtsverhouding tussen erfverpachter en erfpachter zoals die in dit proefschrift wordt geanalyseerd, die zo sterk wordt bepaald door het dwingende goederenrecht en het beginsel van de rechtszekerheid voor derden.

Inhoudelijk biedt in deze dissertatie met name de analyse van Eggens steun - de titel van het proefschrift alludeert op diens '[o]ver de verhouding van eigendom en verbintenis' -, waarin geen scheiding tussen beide begrippen en rechtsgebieden, maar een verhouding wordt voorgestaan tussen personen, waar zowel eigendom als verbintenis, persoonlijke als zakelijke betrekkingen deel van uit kunnen maken. ${ }^{11}$ Het onderzoek van Broese van Groenou vertrekt dan ook vanuit het begrip rechtsverhouding - tussen personen, erfverpachter en erfpachter -, die zowel door goederen- als door verbintenissenrecht wordt genormeerd. Het recht van erfpacht is bij uitstek een voorbeeld waarbij beide rechtsgebieden ten nauwste zijn betrokken, maar het is eenvoudig om door de singuliere plaatsing in het goederenrechtelijke deel van het vermogensrecht op het verkeerde been te worden gezet: Boek 5, zakelijke rechten, art. 5:85 e.v. BW: erfpacht is een zakelijk recht dat de erfpachter de bevoegdheid geeft eens anders onroerende zaak te houden en te gebruiken. De geschiedenis ${ }^{12}$ leert meteen anders: erfpacht was niet alleen een zakelijk recht, het was vooral een verbintenisrechtelijke verhouding, waarbij beide belangen en eveneens publieke belangen ten aanzien van

11. J. Eggens, Over de verhouding tussen eigendom en verbintenis, Amsterdam: N.V. Noord-Hollandsche Uitgevers Maatschappij 1960, waarover het mooie artikel van T.E. Booms, Het dynamisch geheel van eigendom en verbintenis, in: Een man een man, een woord een woord. Werken ter nagedachtenis aan Jannes Eggens (1891-1964), Overveen: Uitgeverij Belvédère 2014, p. 514-539, en waarin ook Eggens' artikel, p. 496-513.

12. Gelukkig nog wat aanwezig in Asser/Bartels \& Van Velten 5 2017/209-211. 
grond werden betrokken. En daarom toch even uw aandacht voor enige vroegere historie, die in deze al zo dikke dissertatie niet zo te vinden is.

\section{Erfelijke pacht}

Erfpacht is niet: pacht van een erf, maar erfelijke pacht. De overeenkomst van gebruik (huur of pacht) van andermans land verandert in een zakenrechtelijk gekleurde verhouding. Dat is op verschillende momenten in de geschiedenis waar te nemen, op verschillende manieren. Zo bijvoorbeeld in het Romeinse recht, waarbij de huurder van grond een zakelijke actie verkreeg, en in de Justiniaanse tijd zelfs als zakelijk gerechtigde werd gezien. Erfpacht werd in de vroegmoderne ordening als verwant met vruchtgebruik gezien - zowel erfpacht als vruchtgebruik was een variatie van zakelijke rechten op andermans zaak. Het onderscheid tussen beide is dat erfpacht niet aan het leven van de gerechtigde is gebonden, zoals bij vruchtgebruik, maar door erfgenamen wordt verkregen. ${ }^{13}$ Dat is de betekenis van 'erf in erfpacht. Overdracht van erfpacht werd eveneens langzaamaan mogelijk. De positie van de erfpachter werd bovendien vrijwel gelijk - dominium utile aan eigenaar, of hij werd het uiteindelijk zelfs, als resultante van wat wel als 'eigendomsverschuiving' wordt aangeduid, ${ }^{14}$ een ontwikkeling die in Asser/Scholten wordt geschetst als 'de neiging dit recht voortdurend sterker te doen worden' ${ }^{15} \mathrm{Uit}$ het verbintenissenrecht is het echter nooit verdwenen - erfpachtgunning is de andere, verbintenisrechtelijke, zijde van dezelfde medaille - aan het begin van de zeventiende eeuw in Grotius' Inleidinge, ${ }^{16}$ en vlak voor de codificaties aan het begin van de negentiende eeuw bij Joannes van der Linden: 'Het regt van erfpacht zelf is eene zoort van gebrekkelijken eigendom, en dus een reeel regt, maar het contract waar bij dit regt gegund wordt, brengt personeele verbintenissen voort.' Het contract heeft zeer veel 'gelijkheid met koop, en ook zeer veel met huur'. Aldus zeer beknopt Van der Linden in 1806, ${ }^{17}$ onder verwijzing naar onder meer De Groots Inleidinge en Voets Pandectencommentaar. Het waren destijds voor de codificatie grote wetenschappelijke autoriteiten die met kracht van de van nature gegeven ratio orde en inhoud brachten in het recht. De plaatsing van een erfpachtverhouding zowel in het goederenrecht als in het verbintenissenrecht is daarmee geen enkel probleem. Met beginselen en met een alomspannende rechtstheorie krijgen de goederenrechtelijke en de verbintenisrechtelijke delen samenhang. Zo brengt Voet de (objectieve) goede trouw - wij zouden nu spreken van de redelijkheid en de billijkheid van art. 6:2 en 6:248 BW - als een

13. H. de Groot, Inleidinge in de Hollandsche rechts-geleerdheid, 1631 (editie Leiden: Universitaire Pers Leiden 1952), II.40.3 (erfpacht), vergeleken met II.39 (vruchtgebruik).

14. A.S. de Blécourt, Kort begrip van het oud-vaderlands burgerlijk recht, Groningen: Wolters-Noordhoff 1969, p. 176-179.

15. C. Asser/P. Scholten, Zakenrecht, Zwolle: Tjeenk Willink 1913, p. 229 (Zwolle: Tjeenk Willink 1927, p. 281) - met andere woordkeuze in Asser/Bartels \& Van Velten 5 2017/210.

16. De Groot 1631, II.40 en III.18.

17. J. van der Linden, Regtsgeleerd, practicaal, en koopmans handboek, Amsteldam: Johannes Allart 1806, p. 165-166. altijd aanwezig grondbeginsel bij erfpacht onder de aandacht. Geen denken aan dat dat in een erfpachtverhouding zou ontbreken, noch tussen de oorspronkelijke bij de vestiging betrokken partijen, noch tussen de latere verkrijgers, erfverpachter en erfpachter, van eigendom en erfpacht. ${ }^{18}$ Voordat het personenrecht, zakenrecht en verbintenissenrecht wordt uiteengezet, behandelt Grotius eerst recht en rechtvaardigheid ${ }^{19}$ - net als Justinianus in diens Instituten - en maakt in die verhandeling klip-en-klaar duidelijk dat willekeurig welke regel - zoals die over de rechtsverhouding die voortvloeit uit erfpachtgunning en erfpacht - in een onverbrekelijk natuurlijk verband staat met de rechtstheorie over recht en rechtvaardigheid. Goederenrecht en verbintenissenrecht zijn niet gescheiden recht en rechtvaardigheid evenmin. Wanneer in een erfpachtverhouding destijds sprake was van toestemming, van canonverhoging, van een einde aan het recht van erfpacht, dan was de goede trouw altijd aanwezig, en dan ging het eens te meer niet alleen om het positieve recht, maar altijd ook om rechtvaardigheid, besloten in natuurrecht, dat door Grotius werd gedefinieerd als 'het oordeel des verstands, te kennen ghevende wat zaken uit haer eighen aerd zijn eerlick ofte oneerlick, met verbintenisse van Gods wegen om hetzelve te volgen'20 etiamsi daremus, non esse deum. ${ }^{21}$ Een dergelijke inspirerende en noodzakelijke opmaat tot de specifieke vermogensrechtelijke regels hebben we in ons wetboek jammer genoeg niet meer. Gelukkig hebben we nu nog het leerstellige discours. Zo slaagt de auteur van dit onderzoek erin om met behulp van met name Eggens die samenhang tussen verbintenissen- en goederenrecht in het erfpachtrecht te bieden in een grote hoeveelheid geanalyseerde rechtspraak over de rechtsverhouding tussen erfverpachter en erfpachter.

\section{De rechtsverhouding in sociaaleconomisch strijklicht}

Over de gehele onderzochte periode, concludeert de auteur, worden door de rechtspraak verbintenisrechtelijke leerstukken als goede trouw, redelijkheid en billijkheid en uitleg van overeenkomsten toegepast in geschillen binnen de erfpachtsverhoudingen. ${ }^{22}$ De diversiteit die in de verschillende opvattingen over de gehele onderzochte periode heen naar voren komt, gaat daardoor in de conclusie wel wat teloor. In de manier waarop die verbintenisrechtelijke beginselen doorwerken in de erfpachtverhouding is nogal wat verscheidenheid te zien, die - als eerder gezegd - rechtstreeks is verbonden met de rechtstheorie. Een paar voorbeelden van uw recensent. Bij Opzoomer krijgt die verbintenisrechtelijke doorwerking voor het erfpachtrecht gestalte vanwege zijn gebruik van logica en de historie bij de duiding van de wetsartikelen over het

18. J. Voet, Commentarius ad Pandectas (Hagae Comitum, apud Anthonium van Dole 1735) I, ad D.6.3.3.

19. De Groot 1631, I.1-2. Idem in Justinianus' Instituten I.1-2, 533 (editie J.E. Spruit c.s., Corpus Iuris Civilis. Tekst en vertaling I, Zutphen/Den Haag: Walburg Pers/Sdu Uitgevers 1993).

20. De Groot 1631, I.2.5.

21. Naar H. de Groot, De iure belli ac pacis, 1625, prolegomena 11.

22. Broese van Groenou 2019, p. 636. 
erfpachtsrecht. $^{23}$ Diephuis gebruikt meer systematiek en wettekst. ${ }^{24}$ De late negentiende eeuw brengt de grote maatschappelijke ongelijkheid onder de aandacht, destijds bekend als 'de sociale kwestie'. De opkomst van erfpacht in de stedelijke grondpolitiek en huisvesting staat daarmee in direct verband - theorieën over rechtsvinding en -vorming eveneens. Die wordt veel vrijer ten opzichte van de wettekst. ${ }^{25}$ Moltzers invloedrijke analyse van erfpacht past naadloos in die maatschappelijke en rechtstheoretische veranderingen. Moltzer geeft zijn werk een motto mee van Gierke: 'Ein Privatrecht, das seinen sozialen Beruf begreift, musz auf die Stetigkeit des Grundbesitzes hinarbeiten. ${ }^{26}$ Dat eigendom bovendien plichten in zich bergt, wordt duidelijk - bijvoorbeeld in de privaatrechtelijke 'zorgplicht' - in een ongelijke duurverhouding als erfpacht. ${ }^{27}$ De verplichtingen van de erfverpachter en erfpachter kunnen op verschillende manieren worden gekwalificeerd, als verbintenis, kwalitatieve verplichting of zakelijke last, als afkomstig uit de wet, overeenkomst of algemene voorwaarden, als meer of minder verband houdend met 'het wezen' (essentie) van het beperkte recht, maar een dergelijke kwalificatie leidt niet noodzakelijk tot afwezigheid van een redelijke toetsing, met weging van de belangen van individuele erfverpachters (eigenaars), erfpachters, derden en publieke belangen. Heel aardig is dat Moltzer ook N.G. Pierson citeert - liberaal, bankier en premier van het 'kabinet van sociale rechtvaardigheid': 'Wil de grondeigendom in onze dagen geerbiedigd worden, hij toone zich eerbiedwaardig. ${ }^{28}$ Destijds betekende dat: grondeigendom dient de publieke belangen van wonen en werken. Tonen van individuele eerbiedwaardigheid in hoedanigheid van eigenaar is in een vrije grond- en huizenmarkt met flink stijgende prijzen nog steeds niet makkelijk. Goed dat er inmiddels ook getoetst wordt aan Europese normen van consumentenbescherming.

Erfpachtvoorwaarden verschijnen met de opkomst van gemeentelijke erfpacht, waarin de rechten en plichten van erf-

23. Zie m.n. C.W. Opzoomer, Aanteekening op de wet, houdende algemeene bepalingen, Den Haag: Gebroeders Belinfante 1848 (4de druk 1884), p. 215.

24. M.n. art. 1269 BW (oud), waarin de bronnen van verbintenis worden gegeven: overeenkomst en de wet. Verbintenissen kunnen ontstaan uit de wettelijke bepalingen in het zakenrecht. Zie voor Diephuis' privaatrechtstheorie onder meer: G. Diephuis, Het Nederlandsch Burgerlijk Regt I (Groningen: J.B. Wolters 1869), par. 3.

25. Een verandering in methode en theorie door Paul Scholten omschreven als ' $[\mathrm{v}]$ an wet naar rechtspraak - van de ontleeding van den tekst naar de bestudeering van rechtsleven en rechtspraktijk - van de logisch sluitende uitspraak naar de intuïtief aanvaarde beslissing'. P. Scholten, Mr. C. Asser's Handleiding tot de beoefening van het Nederlandsch burgerlijk recht. Algemeen deel, Zwolle: W.E.J. Willink 1931, p. 242.

26. J.P. Moltzer, Landbouw en kapitaalbelegging. Eene studie over den privaatrechtelijken grondslag van ons landbouwbedrijf, Haarlem: Tjeenk Willink 1892. O.F. Gierke, Die sociale Aufgabe des Privatrechts. Vortrag gehalten am 5. April 1889 in der Juristischen Gesellschaft zu Wien, Berlin 1889.

27. Broese van Groenou 2019, p. 328, 398 en 469 - onder verwijzing naar onder meer Voncks dissertatie.

28. N.G. Pierson (1839-1909), ten tijde van Moltzers publicatie Minister van Financiën. Ten tijde van dat kabinet (1897-1901) kwamen onder meer de Woningwet en de Arbeidsongevallenwet tot stand. verpachter en erfpachter zijn opgenomen - rechten en plichten betreffende canon, duur, opzegging, bestemming, onderhoud, wegneemrecht opstallen, toestemming voor overdracht, en zo meer. Die erfpachtvoorwaarden zijn inmiddels onderworpen aan de Nederlandse en Europese regelingen inzake onredelijk bezwarende bedingen ${ }^{29}$ en aan de objectieve goede trouw, waar Broese van Groenou natuurlijk ook aandacht aan besteedt. Dat die regelingen van toepassing zijn, is maar goed ook. Hoe ernstig onevenwichtig die voorwaarden kunnen zijn, laten twee vrij recente erfpachtszaken over de mogelijkheid van eenzijdige wijziging door de erfverpachter goed zien. ${ }^{30}$ Uiteindelijk zijn wijzigingsbedingen die erfpacht aan de enkele belangen van de erfverpachter trachten aan te passen, mede dankzij het Europees recht - vooralsnog - gefnuikt. ${ }^{31}$

\section{Over toestemming, canon en het einde van de erfpacht}

Het onderzoek spitst zich toe op een nadere analyse van 'toestemming' van de erfverpachter (voor overdracht, splitsing of een wijziging in de bestemming - hoofdstuk 4), op de canonherziening (hoofdstuk 5) en op het einde van de erfpacht (hoofdstuk 6). Een aantal vragen geeft de auteur houvast: Welke verbintenissen zijn in geschil en wat is de bron (wet, overeenkomst of erfpachtsrecht)? Hoe wordt die gekwalificeerd (verbintenis, kwalitatieve verbintenis of zakelijke last), en heeft zij zakelijke werking? Welk rechtsgevolg is er (inbreuk zakelijk recht of wanprestatie)? Wordt uitgelegd naar woord alleen of worden ook de omstandigheden betrokken? Welke specifieke Boek 6-regel wordt betrokken? Welke recente regels zijn in de jurisprudentie ontwikkeld? Toestemming wordt vaak verbonden aan een voorwaarde, zoals herziening van de canon. Het toestemmingsvereiste wordt getoetst, ook aan de objectieve goede trouw. Zo hoort het. Niet geven van toestemming is onredelijk - een drietal criteria distilleert de auteur uit de jurisprudentie ${ }^{32}-$, indien onoverdraagbaarheid resulteert, indien strijd is met 'de bedoeling van de wetgever en voorwaarden [worden gesteld] die geen verband houden met het afgesproken gebruik van de onroerende zaak', en ten slotte, als er gehandeld wordt in strijd met de erfpachtakte en de erfpachtvoorwaarden. Het zijn oude en bekende redenen die bij eigendom, erfpacht en huur van grond van oudsher aanwezig zijn. Weigering van toestemming kan heel redelijk zijn, bijvoorbeeld om de bestemming van de grond te kunnen bewaken. In het geval van canonverhoging als voorwaarde voor het geven van toestemming is de auteur terecht afwijzend. ${ }^{33}$

Ook los van die toestemming veroorzaken bepalingen die de canon betreffen veel discussie, niet in de laatste plaats omdat

29. Richtlijn 93/13/EEG van de Raad van 5 april 1993 betreffende oneerlijke bedingen in consumentenovereenkomsten, in ons recht in art. 6:231 e.v. BW.

30. Rb. Amsterdam 11 oktober 2017, ECLI:NL:RBAMS:2017:7364; Rb. Amsterdam 20 december 2017, ECLI:NL:RBAMS:2017:9691.

31. Broese van Groenou 2019, p. 251

32. Broese van Groenou 2019, p. 310

33. Broese van Groenou 2019, p. 313 
onvoorzienbare en onbepaalbare herzieningen financiering van verkrijging van erfpacht in de weg staan. Het is niet altijd feest voor een erfverpachter. Als er geen wijzigingsbepaling in de erfpachtvoorwaarden is opgenomen, dan zal wijziging (verhoging) op grond van de onvoorziene omstandigheden en de redelijkheid en billijkheid (zie art. 5:97 BW) niet lukken. Onvergetelijke voorbeelden worden in het onderzoek gepresenteerd. ${ }^{34}$ Iets vergelijkbaars geldt er voor de beëindiging van de erfpacht. Als de woorden in de akte duidelijk zijn, dan past toepassing van art. 5:97 BW niet - ik wijs op de vroeger in ons oude BW aanwezige verbintenisrechtelijke regel in art. 1378 - indien de bewoordingen eener overeenkomst duidelijk zijn, mag men daarvan door uitlegging niet afwijken - interpretatio cessat in claris, ook als het een akte uit 1740 betreft. In dit geval bevatte de akte een ontbindende voorwaarde, die zich na twee eeuwen voordeed. ${ }^{35}$

Geschillen over de canon zijn terug te voeren op een oude grondhouding in onze samenleving: het staat verkoper en koper van nature vrij om bij bepaling van de prijs elkaar 'een beetje te bedonderen', aldus de tweede-eeuwse jurist Pomponius. ${ }^{36}$ Terecht? Bij alle geschillen over wijzigingen in de canon dringt zich de vraag naar de rechtvaardige prijs op, zo komt ook uit de analyse in dit proefschrift naar voren. ${ }^{37} \mathrm{De}$ leer van het iustum pretium, niet middeleeuws, maar Romeins, ${ }^{38}$ en ook in later tijd van grote invloed, ${ }^{39}$ werd in het Franse recht in 1804 opgenomen, maar kwam in 1838 niet in ons BW terecht - 'eene bron van twistgedingen', aldus Carel Asser in zijn vergelijking met het Franse recht. ${ }^{40}$ Alleen de 'redelijke' prijs bleef. Is dat voldoende? Uiteindelijk breekt het zonnetje door, nog een beetje flets, in de zelfregulering, zo blijkt ook uit dit boek. Financiers hebben mede richting gegeven aan de voorwaarden voor canonverhoging - de Nederlandse Vereniging van Banken (NVB) stelde met het notariaat een richtlijn op. ${ }^{41}$ Voorzienbaarheid, bepaalbaarheid en (rechts)zekerheid zullen met die richtlijn beter gewaarborgd zijn. Maar met voorspelbaarheid, bepaalbaarheid en rechtszekerheid alleen wordt een prijs nog niet rechtvaardig. Ook daarvoor zou het Europese consumentenrecht ons een

34. Zoals bijv. Rb. Utrecht 13 oktober 2010, ECLI:NL:RBUTR: 2010:BO0342, waarin de erfpacht eeuwigdurend was uitgegeven, en een beroep op onvoorziene omstandigheden (de enorme prijsontwikkeling van grond) werd ontzegd, zodat geen verhoging van de canon mogelijk was (art. 5:97 BW).

35. Broese van Groenou 2019, p. 474; HR 27 april 2007, ECLI:NL:HR: 2007:AZ9323. Het gebruik van de grond in erfpacht betrof opvang van water, waaraan een einde kwam doordat dat voortaan elders in de polder gestalte kreeg.

36. Instemmend door Ulpianus aangehaald in D. 4.4.16.4.

37. Broese van Groenou 2019, p. 325-331.

38. C. 4.44.2.

39. J. Hallebeek, De iustum-pretium leer en het evenredigheidsbeginsel, AA 2013, afl. 1, p. 59-64.

40. C. Asser, Het Nederlandsch Burgerlijk Wetboek, vergeleken met het Wetboek Napoleon, Den Haag/Amsterdam: De gebroeders van Cleef 1838, par. $742-745$.

41. De bancaire richtlijn financierbaarheid erfpachtrechten, www.nvb.nl/ publicaties/protocollen-regelingen-richtlijnen/bancaire-richtlijnfinancierbaarheid-erfpachtrechten/. helpende hand kunnen bieden, zo argumenteert auteur overtuigend. ${ }^{42}$ Het einde van de erfpacht door ommekomst van de termijn, opzegging door erfverpachter en erfpachter, door vermenging, ${ }^{43}$ en door de rechter krijgt aandacht. Daarbij worden ook de argumentatieve benaderingen van de rechtbanken onderscheiden, zoals de rechtbank ZeelandWest-Brabant, die 'opmerkelijk veel oog [had] voor de gebonden rechtsverhouding waarin partijen zich bevinden bij onderhandelingen over verlenging, en die dan vervolgens toetst aan de redelijkheid en billijkheid en aan de algemene beginselen van behoorlijk bestuur. ${ }^{44}$ In de vlot lezende analyse komen bovendien door het proefschrift heen zeer veel lokale gemeentelijke erfpachtvoorwaarden aan de orde - van Ameland tot Zwijndrecht. Bravo.

\section{Conclusie}

Niet het erfpachtrecht, maar de personen - erfverpachter en erfpachter - worden centraal geplaatst in dit onderzoek, met hun verhouding onderling. Bovendien wordt die verhouding onderzocht 'van onderop' aan de hand van een vrij uitputtend onderzoek van de rechtspraak, over twee eeuwen, goed geschreven, goed geanalyseerd. Dat het moeilijk is algemene conclusies te trekken uit zo'n grote verscheidenheid aan rechterlijke uitspraken, doctrine, wetgeving en zelfregulering verbaast niet, ${ }^{45}$ maar de auteur doet het verfrissend goed, met expliciete aandacht voor de fundamentele analyse over de numerus clausus van Struycken (2007) en toepasselijkheid van de proportionaliteit als door art. 1 Eerste Protocol bij het EVRM. Moet er nader worden gereguleerd? Het antwoord van de auteur - na een zorgvuldig en uitgebalanceerd betoog is zowel ontkennend (niet op grote lijnen) als bevestigend (mogelijk wel op details). Bovendien heeft de auteur aandacht voor zelfregulering en wat zich buiten de landsgrenzen afspeelt. Heel goed. Vrij naar Julius Paulus: het recht volgt lang niet altijd uit de regel, maar de regel eerder uit het recht (D. 50.17.1). Daarvan geeft dit onderzoek uitstekend blijk. De aandacht voor rechtsvergelijking in de conclusie van dit proefschrift doet vermoeden dat er sprake zal zijn van een doorstart na deze geslaagde landing. Mooi - boven de wolken, in het zonnetje, en weer eens naar verre streken!

\footnotetext{
42. Broese van Groenou 2019, p. 330.

43. Zoals gebeurt als gemeenten hun erfpachters in staat stellen de eigendom te verwerven - waarvan de gemeente Utrecht uitgebreid wordt behandeld; zie Broese van Groenou 2019, p. 588 e.v.

44. Rb. Zeeland-West-Brabant 1 juli 2015, ECLI:NL:RBZWB:2015:5207. Broese van Groenou 2019, p. 487-490.

45. Broese van Groenou 2019, p. 634
} 